\title{
Fertility Preservation Methods in Childhood and Adolescence Cancers: A Review
}

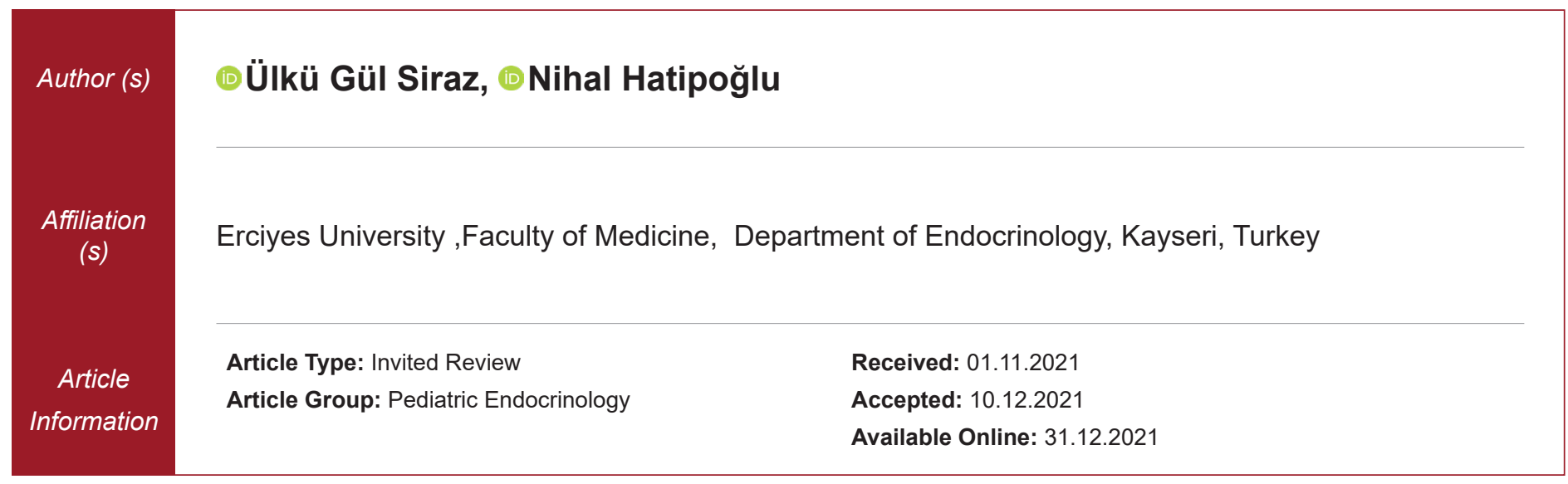

Cite this article as: Siraz ÜG, Hatipoğlu N. Fertility Preservation Methods in Childhood and Adolescence Cancers: A Review. J Pediatr Acad 2021; 3: 91-96.

\section{Abstract}

In childhood and adolescence cancers; survival rates increase with the use of treatment options such as hematopoietic stem cell transplantation, chemotherapy and radiotherapy. One of the long-term effects of primary disease and cancer treatment is the irreversible damage to gonadal tissues, resulting in impaired fertility. Especially chemotherapeutic drugs; causes germ cell defect, affects the secretion of pituitary hormone, and also damages the anatomical structures of internal genital structures such as the uterus.

Gonadal preservation methods are limited in prepubertal male patients. It is a good option to place the testicles in a different area before radiotherapy. Before chemotherapy or whole body irradiation, freezing of testicular tissue and ensuring pregnancy from frozen tissue is still in the experimental stage. After the ejaculation begins, obtaining and storing sperm is successfully done. A limited number of pregnancies were obtained oocytes frozen ovaries in the prepubertal girls. It is possible to freeze oocytes after puberty begins. In addition, recently, as a noninvasive method, gonadotropin-releasing hormone ( $\mathrm{GnRH})$ analogues have been used successfully, as it suppresses the hypothalamic-pituitary-gonadal axis and protects germ cells from cytotoxic effects.

This article aims to provide information on fertility preservation methods in patients receiving childhood cancer treatment

Keywords: Childhood cancers, fertility, gonadal protection

Correspondence: Ulku Gul-Siraz, Erciyes University, Faculty of Medicine, Department of Pediatric Endocrinology, Melikgazi, Kayseri, Turkey

E-mail: dr.ulku.81@hotmail.com 


\section{Introduction}

The survival rates of child and adolescent cancer patients have recently been increasing with the use of different treatment options such as chemotherapy, radiotherapy, and hematopoietic stem cell transplantation (HSCT). In the last decade, pediatric cancer survival rates have exceeded $80 \%$. $^{1}$ These developments have led to a higher desire in patients to have children in the long term.

Before starting cancer treatment, long-term and late effects of the treatment should be considered, as well as its acute side effects. An important issue regarding long-term effects that should be discussed with families is the risk of gonadal dysfunction and infertility. Long-term survival rates have resulted in increased patient concern for fertility, prompting advances in fertility preservation methods. Today, infertility risk and fertility preservation methods are considered together with families before starting cancer treatment to select an appropriate approach to protect gonadal function.

Chemotherapeutic agents, radiotherapy, total body irradiation, and surgical procedures can disrupt gonadal function, causing germ cell defects, affect pituitary hormone secretion, and damage the anatomy of internal genitalia such as the uterus. Although solid tumor and hematologic malignancy treatments have been modified to reduce side effects, there is an ongoing interest in fertility-preserving treatments and assisted reproductive technology.

Alkylating agents are the drugs with the highest level of genotoxicity. These agents, frequently used in childhood cancers, can cause permanent germ cell damage depending on the cancer stage of the patient and the cumulative doses administered. Radiation therapy to the head, spine, pelvis, testicles, or whole body has detrimental effects on pubertal development and eventual fertility. This impact varies depending on the child's age when treated, their susceptibility, and the treatment dose and duration. Besides, the course of the primary disease also impinges on gonadal function (Table 1 and Table 2).
In boys, due to their high mitotic index spermatogonia are highly susceptible to chemotherapy-induced damage, unlike Leydig and Sertoli cells. Posttreatment azoospermia can reach up to $82 \%$, according to the type of chemotherapy. ${ }^{3} \mathrm{~A}$ study on 214 adult male survivors of childhood cancer, who had received chemotherapy including alkylating agents only, reported normospermia in $48 \%$, oligospermia in $28 \%$ and azoospermia in $25 \%{ }^{4}$ Spermatogonia are more sensitive to radiotherapy than adult spermatozoa; 4 Gy may be sufficient for total destruction. Leydig cells are more resistant but can be damaged at doses of 20 Gy at prepuberty and $30 \mathrm{~Gy}$ at puberty. ${ }^{5}$

In women, radiotherapy and chemotherapy can cause premature decrease of the ovarian follicular reserve, resulting in primary ovarian insufficiency (POI) and infertility. $\mathrm{POI}$ is considered menopause before the age of 40 . The absence of menstruation for more than three months should instigate relevant assessment. High follicle-stimulating hormone (FSH) values should also be premonitory in this regard. Another indicator of ovarian reserve in childhood cancer survivors is serum Anti-Müllerian Hormone (AMH) concentration. AMH levels are lower in patients with ovarian insufficiency due to cancer treatment than healthy controls, constituting a vital parameter to guide $\mathrm{POI}$ diagnosis. ${ }^{6}$

Acute ovarian failure occurs in $6 \%$ to $12 \%$ of childhood cancer survivors. ${ }^{7}$ Infertility problems due to decreased ovarian reserve may even occur in women with regular

Table 2

Gonadal dysfunction risks in terms of chemotherapeutic agents ${ }^{2}$

\begin{tabular}{ccc}
\hline Low & Moderate & High \\
\hline Vincristine & Cisplatin & Cyclophosphamide \\
Vinblastine & Carboplatin & Ifosfamide \\
Bleomycin & Doxorubicin & Procarbazine \\
Mercaptopurine & & Chlorambucil \\
Methotrexate & & Chlormethine \\
Dactinomycin & & Melphalan \\
& & Busulfan \\
\hline
\end{tabular}

\begin{tabular}{ccc}
\hline Low & Moderate & High \\
\hline Nephroblastoma & Hepatoblastoma & Testicular or pelvic radiotherapy \\
Acute lymphoblastic leukemia Cerebral tumor & Acute myeloblastic leukemia & Soft tissue sarcoma \\
(surgery alone or with cranial irradiation $<24 \mathrm{~Gy})$ & Soft tissue sarcoma Neuroblastoma & Hodgkin's lymphoma (Alkylating agents) \\
Retinoblastoma & Osteosarcoma & Ewing's Sarcoma (metastatic) \\
Soft tissue sarcoma & Cerebral tumor (cranial irradiation $>24 \mathrm{~Gy}$ ) & Chemotherapy before HSCT \\
Malignant germ cell tumors & Ewing's sarcoma & Total body irradiation \\
& Non-Hodgkin's lymphoma & \\
\hline
\end{tabular}


menstrual cycles after cancer treatment. ${ }^{8}$ The follicle pool is undiminished in the prepubertal period due to the absence of ovulation, so patients receiving chemotherapy are less affected in this period than in the pubertal period. ${ }^{9}$

Ovarian irradiation at doses lower than $2 \mathrm{~Gy}$ is sufficient to destroy the follicles. Since girls are born with an established pool of germ cells, susceptibility to radiationinduced damage increases with age. ${ }^{5}$ Besides, pelvic radiation may adversely affect the uterine muscle and vessels, entailing a reduced uterine volume. Accordingly, an increased risk of pregnancy complications such as preterm birth, miscarriage, or intrauterine growth restriction may ensue. ${ }^{10}$

HSCT is the highest-risk treatment concerning gonadal dysfunction. The most common complication after HSCT for hematological malignancies, POI, develops in more than $90 \%$ of women. ${ }^{11}$

On the other hand, high-dose cranial radiotherapy (35$40 \mathrm{~Gy}$ ) may affect the hypothalamic-pituitary region, causing hypogonadotropic hypogonadism. Decades of cumulative experience have substantiated no increase in congenital malformations in the biological offspring of survivors conceived naturally. ${ }^{12}$

The burden and cost of fertility preservation options differ for girls and boys. The alternatives should be evaluated concerning whether the patient should receive treatment in the preadolescent or postadolescent period. Some treatments are well-established empirically-supported, while others are still tentative. It is crucial to distinguish between clinically approved treatments and experimental ones when advising patients and families on fertility preservation options.

\section{Fertility Preservation Options for Prepubertal Patients}

\section{Prepubertal Boys}

Contemporary methods for gonad and gamete preservation in prepubertal male patients are mainly theoretical, except for testicular shielding or relocation from the field of radiation. Most techniques involve interventions to protect the testicles during cancer treatment. Primordial germ cells are sensitive to toxicity at all stages of puberty. During gonadal-sparing irradiation, the gonads can be temporarily relocated on the thigh or anterior abdominal wall. ${ }^{13}$ This procedure is named as reverse orchiopexy.

Total or partial testicular tissue cryopreservation has mainly remained theoretical and is not routinely practiced. Similarly, testicular transplantation has not been successfully performed in humans yet; nevertheless, the birth of a primate from sperm produced after testicular autotransplantation has been a remarkable milestone. ${ }^{14}$ Besides, animal studies have proven the efficacy of in vitro maturation of frozen testicular tissue as a fertility preservation method. ${ }^{15}$ Currently, testicular tissue cryopreservation is successfully applied in patients ranging between 5 months to 34 years of age, but none of these have resulted in spermatozoa formation from the frozen tissue. ${ }^{16}$ Only one study has reported spermatogonial stem cell transplantation by injection into the rete testes of seven patients treated for nonHodgkin's lymphoma. ${ }^{17}$

Transplantation of testicular tissue is more complicated than similar applications involving the ovaries due to developmental differences between male and female gonads. In any case, testicular tissue cryopreservation may prove valuable since future treatment options may potentially render in vitro maturation or germ cell transplantation a reality.

In addition, the use of angiogenic factors, such as vascular endothelial growth factor, is reported to positively affect revascularization after testicular transplantation. ${ }^{18}$

\section{Prepubertal Girls}

Most fertility preservation methods for girls in the prepubertal period are experimental with unclear longterm results. Using the ovaries to produce mature eggs is not possible in prepuberty, which is also the case for oocyte and embryo cryopreservation. ${ }^{19}$ Besides, oocyte in vitro maturation is still in the experimental phase. ${ }^{20}$

Some authors have recommended ovarian tissue cryopreservation (OTC) to preserve fertility in girls treated for cancer. In contrast to oocyte cryopreservation, functional ovarian tissue is cryogenically stored in OTC (removing part of the ovary or its cortex), which is currently the only promising fertility preservation method in prepubertal cancer patients. ${ }^{21,22}$

Preserving gonadal functions by applying this method is theoretically possible in prepubertal children since the ovaries contains more primary follicles in prepuberty. Once the treatment is complete, the stored ovarian tissue is unfreezed and transplanted back to the donor. Limited viability of autotransplant gonadal tissue, therefore, recovery of endocrine function appears more likely than recovery of reproductive function. ${ }^{23}$ So far, only one live birth after autograft of cryopreserved ovarian tissue in a 9-year-old prepubertal girl has been reported, the youngest case in the literature. ${ }^{24}$

In adult females, more than 70 cases of live birth with cryopreserved ovarian tissue have been published. However, the functioning of the natural ovarian tissue probably enabled these pregnancies instead of the autotransplant tissue..$^{25,26}$

Flow cytometry studies demonstrated the presence of contaminated leukemia cells in normal ovarian tissue samples from patients with leukemia and lymphoma taken before the initiation of therapy. This finding has raised concerns that tumor cells could return to the body after autotransplantation. ${ }^{27}$

Before radiotherapy, oophoropexy can be performed to protect the ovaries by removing them from the radiation field. However, minimal radiation exposure of the gonad may still be possible. In any case, while ovarian transposition is comparatively effective in preserving the endocrine functions of the ovary (almost $60 \%$ ), fertility preservation is much harder, and only $15.3 \%$ of patients can achieve pregnancy. ${ }^{28}$ 


\section{Fertility Preservation Options for Postpubertal Patients}

Fertility preservation is easier in the postpubertal period when obtaining a mature oocyte or sperm is possible.

\section{Adolescent Males}

It is easier to obtain and store semen samples in boys in puberty, especially after ejaculation has begun. Sperm should be collected before cancer treatment to avoid compromising DNA integrity or sample quality. Infertility centers and andrology laboratories facilitate the longterm storage of samples. Some types of cancer, such as testicular cancer, leukemia, and Hodgkin's disease, may reduce sperm quality. ${ }^{29}$

Testicular aspiration or extraction, electroejaculation or obtaining sperm after micturition are alternative sperm retrieval methods. ${ }^{30}$ In vitro maturation of spermatocytes into spermatids has been possible in cases of primary testicular failure without ejaculation, but fertility was rarely achieved. ${ }^{31,32}$

Pregnancy rates are higher with fresh sperm samples than frozen sperm. In cases with low sperm count, fertilization and pregnancy can be achieved by with intracytoplasmic sperm injection. ${ }^{33}$

It has been shown in animal studies that the use of G-CSF (Granulocyte Colony Stimulating Factor) after alkylating agent exposure has a protective and restorative effect on spermatogenesis by stimulating the proliferation of immature spermatogonia. It acts by binding to the surface receptor (CSF3R) of undifferentiated spermatogonia. ${ }^{34}$

Studies in mice have demonstrated that antioxidant agents such as melatonin alleviate busulfan-induced toxicity through the elimination of reactive oxygen radicals and apoptosis inhibition of spermatogonial progenitor cells. ${ }^{35}$

\section{Adolescent Females}

Pregnancy rates of up to $50 \%$ have been reported with cryopreserved oocytes in adult women, with an even higher expectation in younger women and adolescents. ${ }^{36}$

Oocyte cryopreservation before treatment has become routine in patients who are planned for gonadotoxic treatment. ${ }^{37}$ This method involves controlled ovarian hyperstimulation $(\mathrm{COH})$ with subcutaneous gonadotropin hormone injections over approximately ten days. Then, the patient is sedated and the oocytes are collected by fine needle aspiration under the guidance of transvaginal ultrasound. Since this method is invasive, its application in the adolescent age group is limited. In some cases, cancer treatment may need to be started immediately, and a week or more delay may be unacceptable. Besides, adolescents and their parents may be reluctant to ovarian stimulation and egg retrieval due to psychological and emotional reasons. Also, high estrogen levels can be reached during $\mathrm{COH}$, leading to spontaneous ovulation before the eggs are collected. Furthermore, there is a risk of triggering hormone-sensitive cancers. However, these risks are reportedly eliminated using aromatase inhibitors and selective estrogen receptor modulators without causing pregnancy loss. ${ }^{38}$
Babies born from cryopreserved oocytes are increasing day by day, so it has become necessary to investigate their potential health problems and chromosomal abnormalities. Studies have reported a higher rate of birth defects, chromosomal abnormalities or developmental anomalies in these babies than other procedures such as spontaneous pregnancies and IVF. ${ }^{39}$

Evidence has already shown the successful transplantation of cryopreserved ovarian tissue in adults, with more than 90 babies born with this technique so far. About $50 \%$ of these are considered spontaneous fertilization. ${ }^{40,41}$

Pelvic irradiation may cause permanent damage to the uterus, tuba, and vagina, preventing conception or continuation of pregnancy. Parents may have a child through egg donation and surrogacy in such cases, but these are not legal in every country.

If gonadal protection is not possible, gonadotropin suppression may be an option, although its efficacy has not been fully proven. In general, there is limited information on the mechanism of action of gonadotropin-releasing hormone $(\mathrm{GnRH})$ analogs ( $\mathrm{GnRHa}$ ) for gonadal protection, but some evidence suggests their efficacy. Accordingly, rapidly dividing cells are particularly more vulnerable to cytotoxic drugs, and the administration of $\mathrm{GnRHa}$ during cancer treatment may slow their proliferation rate that otherwise leads to gonadal function arrest and protection of cells from apoptosis. In this way, suppression of the hypothalamic-pituitary-gonadal axis leads to decreased egg and sperm production, rendering it more resistant to chemotherapy. ${ }^{42}$ This method cannot be applied in prepubertal girls since the axis is not active yet.

The American Society of Clinical Oncology (ASCO) 2018 guidelines suggest that $\mathrm{GnRHa}$ will be an alternative option for the preservation of gonadal function when other methods are not feasible. ${ }^{43}$

Various studies and meta-analyses have shown that the administration of $\mathrm{GnRHa}$ in combination with chemotherapy reduces $\mathrm{POI}$ and increases the pregnancy rate. ${ }^{44-48}$ Some studies indicate that the combination also improves menstruation, but available data is insufficient to evaluate outcomes for ovarian function and fertility. ${ }^{49}$ Besides, Moore et al. have reported that combined therapy with GnRHa resulted in more favorable disease-free survival and overall survival rates, as well as the preservation of ovarian function. ${ }^{50}$ In another study, lymphoma patients undergoing total body irradiation were started on $\mathrm{GnRHa}$ 10 to 14 days before treatment. The normal ovarian cycle was restored in $66.7 \%$ of the patients who received $\mathrm{GnRHa}$, whereas in $11.1 \%$ of those without GnRHa. The use of $\mathrm{GnRHa}$ is especially considered beneficial in women undergoing HSCT for lymphoma. ${ }^{51}$

The use of GnRHa (triptorelin, goserelin, leuprolide) combined with chemotherapy as a noninvasive, inexpensive, and accessible option to prevent $\mathrm{POI}$ in pubertal and adult patients has recently been integrated into clinical guidelines as well. ${ }^{52,53}$ The updated European Society for Medical Oncology (ESMO) recommendations include using $\mathrm{GnRHa}$ in adolescents and young women, among other options..$^{54,55}$ 


\section{Conclusion}

All the treatment options mentioned above have been a source of hope for the fertility of cancer patients. Fertilitypreserving treatment options should be evaluated by a specialist team of oncologists, radiation oncologists, endocrinologists, urologists, and gynecologists, considering the diagnosis and stage of the primary disease, the chemotherapy to be administered, the gender and pubertal stage of the patient. The patients and their families should be fully informed throughout the process. In the future, standardized fertility preservation protocols must be established for experimental and approved treatment options. A broad range of experimental and clinical studies on this subject is necessary for further advancements.

\section{Conflict of Interest Statement: The authors have no} conflicts of interest to declare.

Financial Disclosure: The authors declared that this study has received no financial support.

Peer-review: Externally peer-reviewed.

\section{References}

1. Siegel RL, Miller KD, Jemal A. Cancer Statistics, 2017. CA Cancer J Clin. 2017;67:7-30. [CrossRef]

2. Wallace WH, Anderson RA, Irvine DS. Fertility preservation for young patients with cancer: who is at risk and what can be offered? Lancet Oncol. 2005;6:209-218. [CrossRef]

3. Rafsanjani KA, Faranoush M, Hedayatiasl AA, Vossough P Gonadal function and fertility in male survivors treated for Hodgkin's disease in Iran. Saudi Med J. 2007;28:1690-1693. [CrossRef]

4. Green DM, Liu W, Kutteh WH, et al. Cumulative alkylating agent exposure and semen parameters in adult survivors of childhood cancer: a report from the St Jude Lifetime Cohort Study. Lancet Oncol. 2014;15:1215-1223. [CrossRef]

5. Wallace WH. Oncofertility and preservation of reproductive capacity in children and young adults. Cancer. 2011;117:23012310. [CrossRef]

6. George SA, Williamson Lewis R, Schirmer DA, et al. Early Detection of Ovarian Dysfunction by Anti-Mullerian Hormone in Adolescent and Young Adult-Aged Survivors of Childhood Cancer. J Adolesc Young Adult Oncol. 2019;8:18-25. [CrossRef]

7. Chemaitilly W, Mertens AC, Mitby $P$, et al. Acute ovarian failure in the childhood cancer survivor study. J Clin Endocrinol Metab. 2006;91:1723-1728. [CrossRef]

8. Trudgen K, Ayensu-Coker L. Fertility preservation and reproductive health in the pediatric, adolescent, and young adult female cancer patient. Curr Opin Obstet Gynecol. 2014;26:372380. [CrossRef]

9. Chemaitilly W, Sklar CA. Endocrine complications in longterm survivors of childhood cancers. Endocr Relat Cancer. 2010;17:R141-R159. [CrossRef]

10. Green DM, Sklar CA, Boice JD Jr, et al. Ovarian failure and reproductive outcomes after childhood cancer treatment: results from the Childhood Cancer Survivor Study. J Clin Oncol. 2009;27:2374-2381. [CrossRef]

11. Tauchmanovà L, Selleri C, De Rosa G, et al. Gonadal status in reproductive age women after haematopoietic stem cell transplantation for haematological malignancies. Hum Reprod. 2003;18:1410-1416. [CrossRef]

12. Seppänen VI, Artama MS, Malila NK, et al. Risk for congenital anomalies in offspring of childhood, adolescent and young adult cancer survivors. Int J Cancer. 2016;139:1721-1730. [CrossRef]

13. Sayan M, Cassidy RJ, Butker EE, et al. Gonadal shielding technique to preserve fertility in male pediatric patients treated with total body irradiation for stem cell transplantation. Bone Marrow Transplant. 2016;51:997-998. [CrossRef]
14. Fayomi AP, Peters K, Sukhwani M, et al. Autologous grafting of cryopreserved prepubertal rhesus testis produces sperm and offspring. Science. 2019;363:1314-1319. [CrossRef]

15. Wyns C, Curaba M, Vanabelle B, Van Langendonckt A, Donnez J. Options for fertility preservation in prepubertal boys. Hum Reprod Update. 2010;16:312-328. [CrossRef]

16. Valli-Pulaski H, Peters KA, Gassei K, et al. Testicular tissue cryopreservation: 8 years of experience from a coordinated network of academic centers. Hum Reprod. 2019;34:966-977. [CrossRef]

17. Radford J. Restoration of fertility after treatment for cancer. Horm Res. 2003;59:21-23. [CrossRef]

18. Ntemou E, Kadam P, Van Laere S, Van Saen D, Vicini E, Goossens E. Effect of recombinant human vascular endothelial growth factor on testis tissue xenotransplants from prepubertal boys: a threecase study. Reprod Biomed Online. 2019;39:119-133. [CrossRef]

19. Salama M, Anazodo A, Woodruff TK. Preserving fertility in female patients with hematological malignancies: a multidisciplinary oncofertility approach. Ann Oncol. 2019;30:1760-1775. [CrossRef]

20. Michalczyk K, Cymbaluk-Płoska A. Fertility Preservation and Long-Term Monitoring of Gonadotoxicity in Girls, Adolescents and Young Adults Undergoing Cancer Treatment. Cancers (Basel). 2021;13:202. [CrossRef]

21. Armstrong AG, Kimler BF, Smith BM, Woodruff TK, Pavone ME, Duncan FE. Ovarian tissue cryopreservation in young females through the Oncofertility Consortium's National Physicians Cooperative. Future Oncol. 2018;14:363-378. [CrossRef]

22. Poirot C, Vacher-Lavenu MC, Helardot $P$, Guibert J, Brugières L, Jouannet P. Human ovarian tissue cryopreservation: indications and feasibility. Hum Reprod. 2002;17:1447-1452. [CrossRef]

23. Meirow D, Ra'anani H, Shapira M, et al. Transplantations of frozenthawed ovarian tissue demonstrate high reproductive performance and the need to revise restrictive criteria. Fertil Steril. 2016;106:467474. [CrossRef]

24. Matthews SJ, Picton H, Ernst E, Andersen CY. Successful pregnancy in a woman previously suffering from $\beta$-thalassemia following transplantation of ovarian tissue cryopreserved before puberty. Minerva Ginecol. 2018;70:432-435. [CrossRef]

25. Meirow D, Levron J, Eldar-Geva T, et al. Pregnancy after transplantation of cryopreserved ovarian tissue in a patient with ovarian failure after chemotherapy. N Engl J Med. 2005;353:318321. [CrossRef]

26. Silber S. Ovarian tissue cryopreservation and transplantation: scientific implications. J Assist Reprod Genet. 2016;33:1595-1603. [CrossRef]

27. Rosendahl M, Andersen MT, Ralfkiær E, Kjeldsen L, Andersen MK, Andersen CY. Evidence of residual disease in cryopreserved ovarian cortex from female patients with leukemia. Fertil Steril. 2010;94:2186-2190. [CrossRef]

28. Aubard Y, Piver P, Pech JC, Galinat S, Teissier MP. Ovarian tissue cryopreservation and gynecologic oncology: a review. Eur J Obstet Gynecol Reprod Biol. 2001;97:5-14. [CrossRef]

29. Eghbali H, Papaxanthos-Roche A. The impact of lymphoma and treatment on male fertility. Expert Rev Hematol. 2010;3:775-788. [CrossRef]

30. Schmiegelow ML, Sommer P, Carlsen E, Sønksen JO, Schmiegelow $\mathrm{K}$, Müller JR. Penile vibratory stimulation and electroejaculation before anticancer therapy in two pubertal boys. J Pediatr Hematol Oncol. 1998;20:429-430. [CrossRef]

31. Tesarik J, Bahceci M, Ozcan C, Greco E, Mendoza C. Restoration of fertility by in-vitro spermatogenesis. Lancet. 1999;353:555-556. [CrossRef]

32. Sofikitis N, Mantzavinos T, Loutradis D, Yamamoto $Y$, Tarlatzis V, Miyagawa I. Ooplasmic injections of secondary spermatocytes for non-obstructive azoospermia. Lancet. 1998;351:1177-1178. [CrossRef]

33. Habermann H, Seo R, Cieslak J, Niederberger C, Prins GS, Ross L. In vitro fertilization outcomes after intracytoplasmic sperm injection with fresh or frozen-thawed testicular spermatozoa. Fertil Steril. 2000;73:955-960. [CrossRef]

34. Kotzur T, Benavides-Garcia R, Mecklenburg J, Sanchez JR, Reilly M, Hermann BP. Granulocyte colony-stimulating factor (G-CSF) promotes spermatogenic regeneration from surviving spermatogonia after high-dose alkylating chemotherapy. Reprod Biol Endocrinol. 2017;15:7. [CrossRef]

35. Zhang $X$, Xia $Q$, Wei $R$, et al. Melatonin protects spermatogonia from the stress of chemotherapy and oxidation via eliminating reactive oxidative species. Free Radic Biol Med. 2019;137:74-86. [CrossRef] 
36. Cobo A, García-Velasco JA, Coello A, Domingo J, Pellicer A, Remohí J. Oocyte vitrification as an efficient option for elective fertility preservation. Fertil Steril. 2016;105:755-764.e8. [CrossRef]

37. ACOG: Committee Opinion No. 584: oocyte cryopreservation. Obstet Gynecol. 2014;123:221-222. [CrossRef]

38. Oktem O, Oktay K. Fertility preservation for breast cancer patients. Semin Reprod Med. 2009;27:486-492. [CrossRef]

39. Noyes N, Porcu E, Borini A. Over 900 oocyte cryopreservation babies born with no apparent increase in congenital anomalies. Reprod Biomed Online. 2009;18:769-776. [CrossRef]

40. Demeestere I, Simon P, Dedeken L, et al. Live birth after autograft of ovarian tissue cryopreserved during childhood. Hum Reprod. 2015;30:2107-2109. [CrossRef]

41. Gellert SE, Pors SE, Kristensen SG, Bay-Bjørn AM, Ernst E, Yding Andersen C. Transplantation of frozen-thawed ovarian tissue: an update on worldwide activity published in peerreviewed papers and on the Danish cohort. J Assist Reprod Genet. 2018;35:561-570. [CrossRef]

42. Meistrich ML, Shetty G. Hormonal suppression for fertility preservation in males and females. Reproduction. 2008;136:691701. [CrossRef]

43. Oktay K, Harvey BE, Partridge AH, et al. Fertility Preservation in Patients With Cancer: ASCO Clinical Practice Guideline Update. J Clin Oncol. 2018;36:1994-2001. [CrossRef]

44. Lambertini $M$, Falcone $T$, Unger JM, Phillips KA, De Mastro L, Moore HC. Debated Role of Ovarian Protection With Gonadotropin-Releasing Hormone Agonists During Chemotherapy for Preservation of Ovarian Function and Fertility in Women With Cancer. J Clin Oncol. 2017;35:804-805. [CrossRef]

45. Lambertini M, Ceppi M, Poggio F, et al. Ovarian suppression using luteinizing hormone-releasing hormone agonists during chemotherapy to preserve ovarian function and fertility of breast cancer patients: a meta-analysis of randomized studies. Ann Oncol. 2015;26:2408-2419. [CrossRef]
46. Shen YW, Zhang XM, Lv M, et al. Utility of gonadotropin-releasing hormone agonists for prevention of chemotherapy-induced ovarian damage in premenopausal women with breast cancer: a systematic review and meta-analysis. Onco Targets Ther. 2015;8:3349-3359. [CrossRef]

47. Del Mastro L, Ceppi M, Poggio F, et al. Gonadotropin-releasing hormone analogues for the prevention of chemotherapy-induced premature ovarian failure in cancer women: systematic review and meta-analysis of randomized trials. Cancer Treat Rev. 2014;40:675-683. [CrossRef]

48. Wang C, Chen M, Fu F, Huang M. Gonadotropin-Releasing Hormone Analog Cotreatment for the Preservation of Ovarian Function during Gonadotoxic Chemotherapy for Breast Cancer: A Meta-Analysis. PLoS One. 2013;8:e66360. [CrossRef]

49. Elgindy E, Sibai H, Abdelghani A, Mostafa M. Protecting Ovaries During Chemotherapy Through Gonad Suppression: A Systematic Review and Meta-analysis. Obstet Gynecol. 2015;126:187-195. [CrossRef]

50. Moore HC, Unger JM, Phillips KA, et al. Goserelin for ovarian protection during breast-cancer adjuvant chemotherapy. $N$ Engl $J$ Med. 2015;372:923-932. [CrossRef]

51. Blumenfeld Z, Patel B, Leiba R, Zuckerman T. Gonadotropinreleasing hormone agonist may minimize premature ovarian failure in young women undergoing autologous stem cell transplantation. Fertil Steril. 2012;98:1266-70.e1. [CrossRef]

52. AIOM. Linee guida per la preservazione della fertilità nei pazienti oncologici. Italian Association of Medical Oncology (AIOM) (2020).

53. National Comprehensive Cancer Network (NCCN) Guidelines. Available at: [CrossRef] (Accessed January 2021).

54. Oktay K, Harvey BE, Partridge AH, et al. Fertility Preservation in Patients With Cancer: ASCO Clinical Practice Guideline Update. J Clin Oncol. 2018;36:1994-2001. [CrossRef]

55. Dolmans MM, Taylor HS, Rodriguez-Wallberg KA, et al. Utility of gonadotropin-releasing hormone agonists for fertility preservation in women receiving chemotherapy: pros and cons. Fertil Steril. 2020;114:725-738. [CrossRef] 